\title{
Advances in Genomics-Based Breeding of Barley: Molecular Tools and Genomic Databases
}

\author{
Asad Riaz ${ }^{1,+}\left(\mathbb{D}\right.$, Farah Kanwal ${ }^{1,+}$, Andreas Börner ${ }^{2,3}$, Klaus Pillen ${ }^{3}$, Fei Dai ${ }^{1, *}$ and Ahmad M. Alqudah ${ }^{3, *(D)}$ \\ 1 College of Agriculture and Biotechnology, Zhejiang University, Hangzhou 310058, China; \\ asad.riaz76@gmail.com (A.R.); 11816105@zju.edu.cn (F.K.) \\ 2 Leibniz Institute of Plant Genetics and Crop Plant Research (IPK), Corrensstraße 3, \\ 06466 Seeland, Gatersleben, Germany; boerner@ipk-gatersleben.de \\ 3 Institute of Agricultural and Nutritional Sciences, Martin Luther University Halle-Wittenberg, \\ Betty-Heimann-Straße 3, 06120 Halle (Saale), Germany; klaus.pillen@landw.uni-halle.de \\ * Correspondence: daifeijx@163.com (F.D.); ahmad.alqudah@landw.uni-halle.de (A.M.A.) \\ + Authors contributed equally.
}

check for updates

Citation: Riaz, A.; Kanwal, F.; Börner, A.; Pillen, K.; Dai, F.; Alqudah, A.M Advances in Genomics-Based Breeding of Barley: Molecular Tools and Genomic Databases. Agronomy 2021, 11, 894. https://doi.org/10.3390/ agronomy11050894

Academic Editor: Ryan Whitford

Received: 13 March 2021

Accepted: 30 April 2021

Published: 2 May 2021

Publisher's Note: MDPI stays neutral with regard to jurisdictional claims in published maps and institutional affiliations.

Copyright: (c) 2021 by the authors. Licensee MDPI, Basel, Switzerland. This article is an open access article distributed under the terms and conditions of the Creative Commons Attribution (CC BY) license (https:/ / creativecommons.org/licenses/by/ $4.0 /)$.

\begin{abstract}
Barley is the fourth most important cereal crop and has been domesticated and cultivated for more than 10,000 years. Breeding climate-smart and stress-tolerant cultivars is considered the most suitable way to accelerate barley improvement. However, the conventional breeding framework needs to be changed to facilitate genomics-based breeding of barley. The continuous progress in genomics has opened up new avenues and tools that are promising for making barley breeding more precise and efficient. For instance, reference genome assemblies in combination with germplasm sequencing to delineate breeding have led to the development of more efficient barley cultivars. Genetic analysis, such as QTL mapping and GWAS studies using sequencing approaches, have led to the identification of molecular markers, genomic regions and novel genes associated with the agronomic traits of barley. Furthermore, SNP marker technologies and haplotype-based GWAS have become the most applied methods for supporting molecular breeding in barley. The genetic information is also used for high-efficiency gene editing by means of CRISPR-Cas9 technology, the best example of which is the cv. Golden Promise. In this review, we summarize the genomic databases that have been developed for barley and explain how the genetic resources of the reference genome, the available state-of-the-art bioinformatics tools, and the most recent assembly of a barley pan-genome will boost the genomics-based breeding for barley improvement.
\end{abstract}

Keywords: barley; genome; next-generation sequencing; databases; genomic breeding

\section{Introduction}

Barley (Hordeum vulgare, $2 \mathrm{n}=2 \mathrm{x}=14$ ) -domesticated from its wild relative, Hordeum spontaneum, which was found at archaeological sites in the Fertile Crescent over 10,000 years ago - and was the first crop cultivated by humans [1], and today, it ranks as the fourth largest cereal crop in terms of planting area (http: / / faostat.fao.org, accessed on 21 January 2021). It is a major food source in some developing countries [2], as it can tolerate more environmental stresses than wheat and other cereals [3].

Concentrating on the important agronomic traits of barley, such as the number of tillers [4], grain number [5], plant height [6], disease resistance [7], abiotic stress tolerance [8], and malting quality [9], plant breeders have made efforts towards advanced molecular breeding in order to attain the best combination of traits for satisfying farmers' and consumers' demands.

Next-generation sequencing (NGS) technology has sped up the progress of the genome sequencing and re-sequencing of cereal crops, with huge potential for making a remarkable impact on breeding [10]. The published genome sequences of rice [11], wheat [12], maize [13], barley [14], and other cereal crops have supported researchers in determining 
the genetic and physical mapping of molecular markers in specific loci/genes. These identified markers can be applied on the basis of genotyping technology to conduct molecular marker-assisted selection (MAS) breeding or to determine the genetic relationships among diverse accessions. The reference genomes are used for re-sequencing to frame a bulk segregation analysis (BSA) of individuals and to analyze sequence diversity at the genomic level [15]. The BSA-Seq combination of whole-genome sequencing (WGS) has been applied for quick identification of mutations (nucleotide changes) using MutMap and quantitative trait loci (QTL) in major cereals [16]. Some other sequencing-based genomic approaches that have been utilized in barley include bulk segregant ribonucleic acid (RNA) sequencing (BSR-seq) [17], specific-length amplified fragment sequencing (SLAF-seq) [18], and genome-wide association scan (GWAS) [19]. The development of transcriptome sequences has improved the interpretation of genes with an understanding of the domestication and regulation of gene function networks using their expression patterns. In addition to the identification of genetic markers and the availability of published genomes, clustered regularly interspaced short palindromic repeats-associated protein 9 (CRISPR/Cas9) is promising for application to modern breeding and is a novel technology for genome editing in major cereals [20]. CRISPR/Cas9-based directional breeding is highly efficient and saves more time than other breeding techniques that use genome editing [21].

Here, we review the advances in the application of NGS in barley breeding and outline the applications of genome editing in modern breeding. Moreover, this review summarizes the genomics-based approaches to gene identification and sheds light on the availability of genomic resources and databases for barley. This effort can provide a theoretical groundwork which will help to develop knowledge-based strategies for further adaptation of barley to our needs.

\section{Brief Description of the Available Genomic/Transcriptomic Information and Databases}

The open availability of sequencing data of barley has enhanced the understanding of the genetic and regulatory functions of genes related to agronomically important phenotypes. The genome size of barley is almost $5100 \mathrm{Mb}(\sim 5.1 \mathrm{~Gb})$ [22], and the first reference genome was established by the International Barley Sequencing Consortium (IBSC) [23]. There are several databases available for barley genome sequence data (see Figure 1), which contain different information and offer different tools for the interpretation of genomic resources and analysis.

\subsection{EnsemblPlants}

EnsemblPlants is a web database that acquires the genomic and proteomic data of different plant species, including barley [24], and also offers access for application of the Basic Local Alignment Search Tool (BLAST) to check the index of similarity of the queried sequence with the barley genome. It manages data with the collaboration of the Gramene Database [25].

\subsection{Nord-Gen}

Nord-Gen (Nordic Genetic Resource Center) is an international database for genetic stock and mutant data collection that is centered in Sweden. Now, it is a gene bank as well as a center for genetic resources. It houses information on barley genes, mutants, and gene nomenclature.

\subsection{BARLEX}

BARLEX presents the first linearly ordered barley sequence and provides physical and genetic maps of molecular markers and genes using different version of assembly and gene set, with the expression profiling data of 16 developmental stages, as well as exome capture data [14]. 


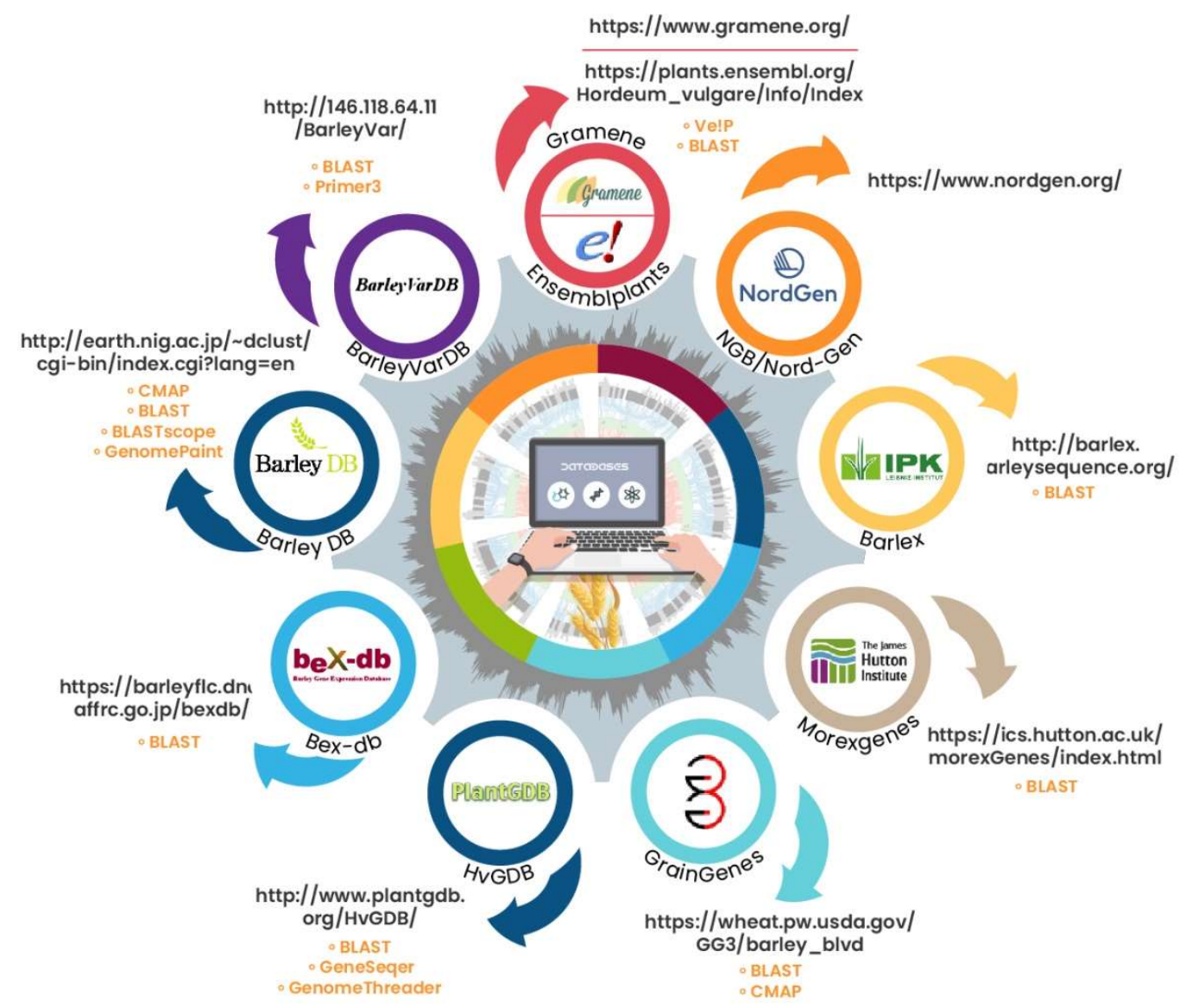

Figure 1. Compilation of quick and short information on the major barley genome databases. Each small, colored circle introduces a different database (name under each circle), with the arrows pointing to the addresses of their webpages. The yellow-colored text under the webpage links shows the names of the tools offered in that database.

\subsection{MorexGenes}

MorexGenes offers access to gene expression levels from the RNA-seq data of the barley cultivar, Morex, which are assembled from whole-genome shotgun sequences of Morex. It also contains a BLAST tool for carrying out basic alignments [26,27].

\subsection{GrainGenes}

GrainGenes is a genetic database primarily containing data on barley and wheat, such as genetic markers, gene expression, and QTLs. It also provides tools for BLAST, genome-specific primer design, and a genetic map display/visualizer [28].

\section{6. $H v G D B$}

HvGDB is a barley database provided by PlantGDB (Plant Genome DataBase) that offers a focus on comparative genomics by using genomic data integration and analysis. It contains advanced tools for comparative genomics, such as CrowsNest, which is used to analyze syntenic relationships among grass genomes.

\section{7. $B e x-D B$}

Bex-DB was developed by the National Institute of Agrobiological Sciences (NIAS) with the availability of full-length cDNA libraries of a two-rowed malting barley, Haruna Nijo. It offers BLAST, a genome viewer for IBSC, and comprehensive analysis of gene expression data [22]. 


\subsection{BarleyDB}

BarleyDB includes material on barley germplasms and genome resources, as well as BLAST and extra tools (http://shigen.nig.ac.jp/shigen/tool/tool.jsp?lang=en, accessed on 16 January 2021), such as BLASTscope, which enables the creation of graphical figures of BLAST query results, and GenomePaint, which enables the creation of graphical figures (circular or linear) of a specified genomic region.

\subsection{BarleyVarDB}

BarleyVarDB is a recently established database that provides data related to barley's genomic variations in the form of three datasets-SNPs, InDels, and whole-genome sequences of wild (eight accessions) and cultivated (13 accessions) barley genomes-with a web-based application of BLAST with Primer3 [29].

\section{Mapping and Identification of Useful Genomic Regions/Genes Using the Established Genetic Information/Genomic Resources}

With the completion of the barley genome sequence and the open availability of the databases, barley breeding is now in the "genomic" era, while barley research is in the post-genomic era. Genome-based identification and utilization have progressively become the core techniques for identifying gene functions. Several genomic databases for barley have been established, and they are being utilized in different ways to identify or map the specific genes or genomic regions. The main approaches for the genome-based association studies utilized in barley are shown in Figure 2 and discussed below.

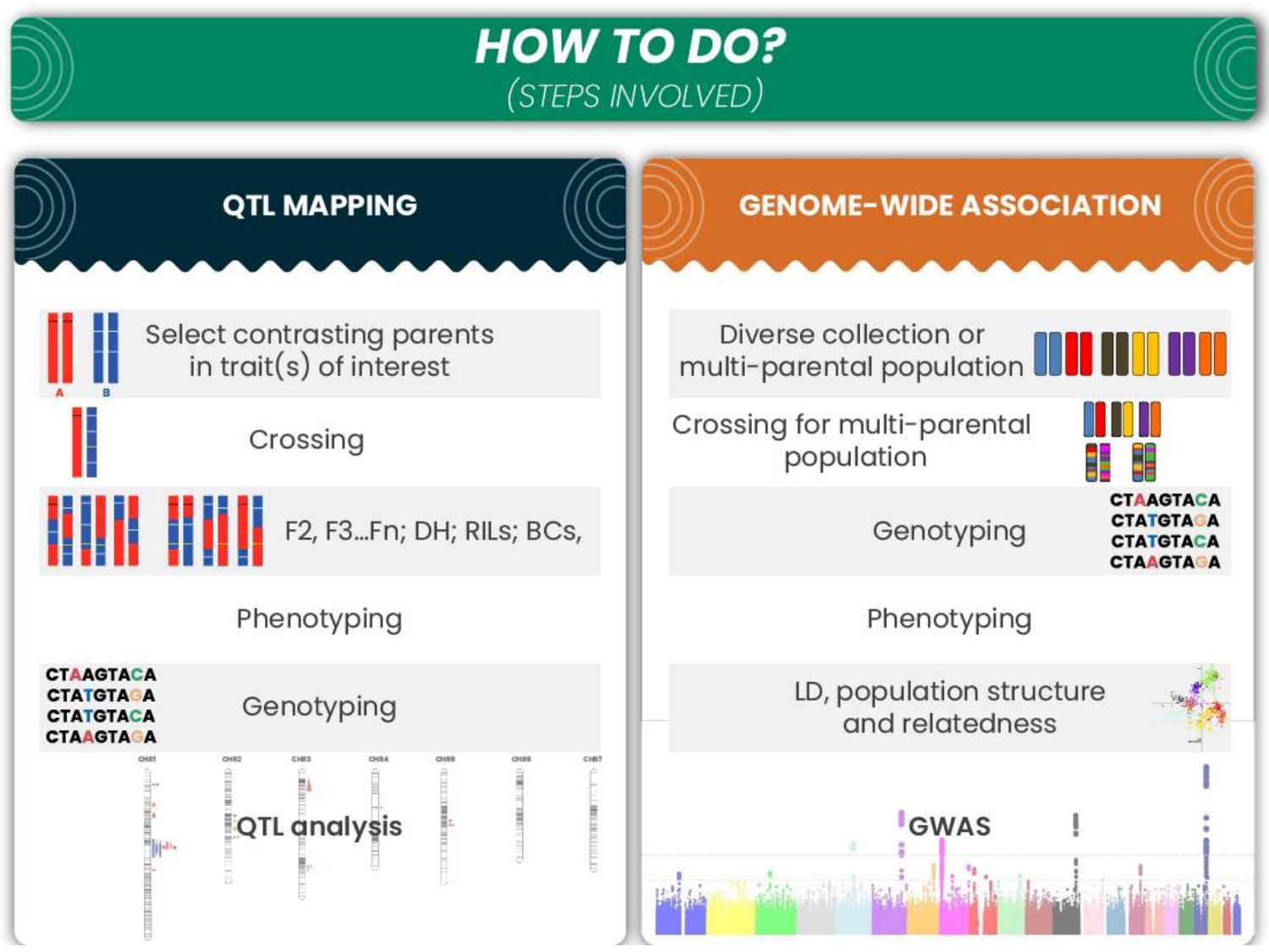

Figure 2. Brief description of the major steps involved in QTL mapping and GWAS.

\subsection{Quantitative Trait Locus (QTL) Mapping}

QTL mapping is a statistical-analysis-based technique that integrates the phenotype of a specific trait (phenotypic data) with molecular markers (genotypic data) in a developed 
population to determine a genetic region (QTL) in complex characters [30]. A number of QTL statistical models have been developed, such as standard interval mapping (SIM) and multiple imputation (IMP), which are used when the single QTL is unlinked, and composite interval mapping (CIM), which is designed to map the genetic linkage for both linked and unlinked QTLs/genes on the chromosome. The performance of these methods is measured based on the calculated LOD (logarithms-of-odds) scores, and QTLs are usually considered significant above the threshold LOD score of 3.0. Open access to reference genomes helps researchers by providing genetic information on the genes responsible for QTLs, which are the target of MAS. Traditional QTL mapping requires a balanced population with known recombination data. Following this, a statistical association can be inferred between phenotypic and genotypic data through linkage mapping [31,32]. The location of a QTL can be determined where the allelic variants of a physically or genetically linked molecular marker display a significant effect on a quantitative trait in the studied population [32]. The identification of genomic locations facilitates the further identification of responsible genes and the exploration of the mechanism of genetic variation [33]. Like in other crop plants, the linkage or QTL mapping approach is widely applied in barley, and its power to identify QTLs that control target traits in a specific population has been proven. In barley, dozens of populations have been developed and used for QTL studies using genetic markers, either RFLPs $[34,35]$ or SSRs $[18,36]$. NGS dramatically improves the density of SNPs; thus, researchers are empowered to detect QTLs for various traits. A sets of 47 introgression lines were used to map drought-tolerance-related QTLs, and 11 out 44 QTLs were found to be involved in the growth rate and water-use efficiency [37]. A population of 100 recombinant inbred lines (RILs) of barley derived from a cross between Syrian and European parents was used to identify the grain-yield-related QTLs, and a total of 60 QTLs were mapped, with the largest number on $2 \mathrm{H}$ associated with the heading [38]. The mapping of a population of 93 recombinant inbred lines (RILs) developed from a cross between the "Rasmusson" cultivar, which was moderately susceptible to fusarium head blight, and a highly susceptible Japanese landrace was used to identify the QTLs associated with susceptibility to disease in barley, which resulted in a total of six QTLs being identified on the $2 \mathrm{H}, 5 \mathrm{H}, 6 \mathrm{H}$, and $7 \mathrm{H}$ chromosomes [39]. For nutrient-use efficiency, 17 QTLs associated with phosphorus (P) acquisition and P-use efficiency [40] were identified, and 15 QTLs related to nitrogen-use efficiency under low nitrogen were identified in 94 recombinant inbred lines (RILs) of the Prisma $\times$ Apex mapping population [41,42]. Similarly, a number of QTLs related to malting quality were identified [43,44], and phenolic compounds were found to be associated with agronomic traits [45]. As an example of NGS application in barley, genotyping by sequencing (GBS) was used for QTL analysis in a family of recombinant inbred lines (RILs) to detect the Breviaristatum-e (ari-e) locus [46]. QTL mapping remains a strong approach that is recommended for identifying QTLs in barley, especially with the recent advancements in NGS. QTL mapping requires genetically diverse biparental segregating populations, and the diversity of the populations may affect the detected QTLs. In general, QTL mapping shows genomic regions that affect the genotype through loci associated with a trait, but is unable to identify the specific genomic loci, i.e., SNPs. The limitations of QTL analysis can be overcome by using GWAS, which can narrow down the candidate genomic regions using naturally diverse populations based on linkage disequilibrium (LD).

\subsection{Genome-Wide Association Study (GWAS)}

Like QTL mapping, GWAS also uses statistical association mapping (AM) between the molecular marker and the trait of interest. With diverse populations and based on LD without known recombination, the historical recombination can be handled. The LD could be the result of physical linkage, as well as genetic drift, selection after mutation, and population structure [47]. GWAS interprets the associations of each marker and trait of interest, which are evaluated using the individuals of a diverse population [48]. A major problem in AM is the control of false positives, which can arise due to the population 
structure and family relatedness. False positives are often controlled by incorporating covariates for structure and kinship in mixed linear models (MLMs). These MLM-based methods are single-locus models and can introduce false negatives. A number of statistical tools ((MLM, compressed MLM (CMLM), ECMLM, multi-locus mixed model (MLMM), general linear model (GLM), and fixed and random model circulating-probability unification (FarmCPU)) were applied for AM in order to find significant markers. It was reported that the FarmCPU-based GWAS model could perform better compared to the other models, as it efficiently controlled for false-positive associations [49]. With the fast growth and availability of sequencing technologies, GWAS is now a prevailing tool for determining the loci underlying the natural variations in different traits of crops [48]. In GWAS, the population needs to be genotyped once; subsequently, it can be utilized repeatedly for the mapping of different traits using new phenotypic data [48]. GWAS has the limitation of its high rates of false positives due to population structures and genetic relationships.

GWAS studies have been conducted in barley for more than a decade [50]. The recently developed $9 \mathrm{~K}$ and 50K iSelect SNP array has strongly enhanced the efficiency of the GWAS tool for novel QTLs/gene detection in barley [51]. For instance, gene targets important agronomic traits, such as the HvCO-like genes; some novel QTLs associated with the heading were identified with the application of GWAS in a mixed spring barley population with photoperiod sensitivity and reduced photoperiod sensitivity [52]. A population of 218 accessions of spring barley (mixed two-row and six-row) was employed in a GWAS-based analysis for the genetic dissection of the effect of the row type on the number of productive tillers [6]. In another GWAS-based analysis, some yield-related traits were examined to identify associated novel genes in a population of 615 barley cultivars, and two novel chromosomal associations with seed germination were found [53]. In addition, GWAS analyses of disease resistance against, for example, spot blotch, leaf rust, and stripe rust [54], as well as for malting and beer quality traits, were successfully carried out [55]. In addition to natural populations, family-based populations, such as the nested association mapping (NAM) population [56] and multi-parent advanced generation intercross (MAGIC) populations [57], were analyzed through GWAS in barley. They proved their utility in uncovering the basis of key agronomic traits in barley $[58,59]$. The most frequently used markers for GWAS are SNPs, but the exploration of the complex relationships between quantitative phenotypes and biallelic SNPs is limited [60,61]. Later, this limitation can be overcome through the analysis of haplotype blocks in targeted regions associated with complex traits [62]. A recent study was conducted to compare single-SNP-, multi SNP-, and haplotype-based GWAS analyses in barley, and much better results were found with the construction of haplotype blocks [63]. A number of studies have focused on the application of GWAS in barley [64-66]. In a recently presented review, we described the genetic discoveries in barley and provided a layout about how the GWAS tools can be utilized in barley breeding programs [67].

\subsection{Integration Bridge: A Way to Overcome the Limitations of QTL Mapping and GWAS}

Considering the limitations of each approach, an integrative bridge between both techniques can be a powerful approach for the genetic dissection and identification of the loci associated with a trait of interest. This combination compensates for the limitations resulting from false positives and facilitates the detection of rare or small-effect QTLs with high-resolution identification [68]. The output of GWAS is considered an excellent step for selecting true segregating parents in order to develop populations depending on their contrasting situations in specific phenotypes and genomic regions (allele(s)). The detection of genomic regions for the same trait in both populations with these mapping strategies is a genetic validation of the QTLs. Hence, it is best to combine both mapping strategies for the most accurate QTL results, which can be used for further genetic and molecular analyses. A rapid detection of loci responsible for complex traits was shown by using this approach in rice; 200 rice varieties in an association population together with 192 RILs were used, and reliable loci that were responsible for seed vigor were identified with the simultaneous 
application of QTL mapping and GWAS [68]. In barley, the combination of both mapping populations has not yet been applied, but it is a promising approach that constitutes a step forward in genetic analysis and in the identification of candidate genes.

\subsection{Genome-Wide Analysis or Identification of Gene Families}

The robust sequencing technology and openly available genome databases provide a great opportunity for researchers in genomic analysis. Bioinformaticians are focusing on the development of new methods for analyzing the available genomic datasets [69]. A number of strategies and tools have been developed for comparative genomics or genome-wide analysis [70-72]. Of these, genome-wide identification has been applied to identify the members of specific gene families of transcription factors by using the reference genomes and phylogenetic analysis of closely related species [73]. This provides potential insights for exploring the regulatory mechanism and functional foundation of a gene family that encodes a specific protein. Several strategies are applied in such studies, including the following three: (i) identification of gene family members using gene annotations, which requires a large genome, and the annotation should be correct, as an error in the annotation raises the chances of false-positive sequences; (ii) family members can be identified by using the BLAST tool in public databases; the query sequences are usually from model species, e.g., Arabidopsis; this could result in fewer family members being identified due to the presence of species-specific genes, but it is beneficial to identify gene family members with non-canonical domains; (iii) gene family members can be identified using the HMMER program [74], which is based on hidden Markov models; this program can be used to generate a file (HMM) of gene families, and it can also identify distant gene family members with a better gene representation [74]. Several studies have been conducted, and they focused on genome-wide analysis of the evolution, identification, and regulatory network, and expression of gene families in barley, such as the signal transduction cascade (MAPK/KK/KKK; mitogen-activated protein kinase/kinase kinases/kinase kinase kinases) involved in biotic and abiotic stresses, were subjected to genome-wide identification, and 20 MAPKs, six MAPKKs, and 156 MAPKKKs of the MAPK family were identified in barley [75]. The potential function of nuclear factor-Ys (NF-Ys), which facilitate salt-stress tolerance, was determined by identifying the co-expression of 23 members in barley [76]. The epidermal wax-related stress resistance is associated with $\beta$-ketoacyl CoA synthetase (KCS) genes, and $33 \mathrm{KCS}$ gene family members were found to be evenly distributed in barley chromosomes. [77]. The Hsp20 gene family, which is associated with heat-shock tolerance, has 38 putative members in barley [78]. Similarly, genes regulated under heavy metal stress were identified using barley transcriptomic data [79], and plant-phytohormonerelated gene families that are involved in different developmental stages were also subjected to these bioinformatics-based gene identification techniques [80].

\section{Genome-Based Molecular Breeding}

The progress in genomics and access to publicly available genomic databases has enhanced existing breeding methods, which has facilitated the development of novel approaches to barley breeding. Modern breeding is basically a strategy for evaluating the genetic gain of a new genotype by separating the genetic effects from the environmental and noise components [81]. Plant breeding is based on different strategies, such as traditional selection by using phenotypic data for genetic evaluation [81], MAS based on specific genetic markers associated with the relevant trait, where individuals are selected based on their marker scores [82], or genomic selection, which is an advanced way of selecting individuals based on genetic markers with small effects on phenotypic variation. The steps involved in the process of genome-based molecular breeding are shown in Figure 3. MAS breeding has numerous advantages over traditional breeding, such as the lack of the need to permanently generate phenotypic data if traits are complex, its cost effectiveness, and time consumption, which impedes phenotyping, for example, with malting quality. MAS is a quick process that does not require the phenotype testing of huge progeny sets, and 
pyramiding of multiple alleles is possible [83]. In addition, the linkage drag is reduced [84], and the genetic gain is increased compared to the use of phenotypic selection [85]. The genetic merit of an individual can be evaluated by using a larger population size without compromising the genetic gain by narrowing the genetic diversity [85]. MAS-based breeding programs have been extensively conducted in other cereals like wheat and rice, and it is suggested to further utilize this breeding application in barley for yield-related and stresstolerant traits, as MAS has proven to be successful in barley, with the identification of elite lines of improved malting quality by stable transfer of the thermostable $\beta$-amylase from wild barley into a commercial variety [86]. With the development of NGS technologies, the number of markers has been increased, and the breeding efficiency has significantly increased. SSRs, SNPs, InDels, and haplotypes have become the most important markers to use for efficient genotyping and construction of genetic maps. For example, SSR markers were employed to map the Als gene on the $3 \mathrm{H}$ chromosome of barley, and it was found to be responsible for the low number of tillers [87]. In a study of barley, a total of 83 significant marker-trait associations were found to be associated with six different yield-related traits under drought conditions [88]. A similar thousand-SNP-marker set was used for association mapping of salt tolerance in barley [89]. A semi-dwarfness gene in barley, ari-e, was mapped using SNPs and InDels in a $10 \mathrm{Mb}$ to $0.58 \mathrm{Mb}$ interval on the POPSEQ physical map [90]. Different strategies (Sections 3.1 and 3.2) have been applied for the identification of QTLs of relevant traits in barley for marker identification and utilization, which strongly enhanced the genomic-based molecular breeding of barley, e.g., through MAS. Genome-wide selection is also known as genomic selection (GS) and is a new breeding strategy with potential for significant outcomes in plant breeding [91]. In GS, a genetically diverse test population is thoroughly genotyped and phenotyped to predict its phenotypic performance based on genomically estimated breeding values (GEBVs). The large breeding population is then genotyped, and the GEBVs are used to predict the phenotypes of the lines of the population. GS has emerged as a valuable tool for improving complex traits that are controlled by QTLs with small effects. Various simulation models for predicting the selection accuracy depend largely on the marker density, marker type, size of training populations, and trait heritability. Compared with QTL mapping and GWAS, GS has more promise for harnessing genetic gains from genetic resources for quantitative traits, and it is seen as a more reliable and useful approach [92]. It has been applied in barley breeding, such as in a study conducted by the University of Minnesota, where six-row barley lines were evaluated for GS; a significant gain in grain yield of $186.1 \mathrm{~kg} / \mathrm{ha}$ was obtained, and $1.85 \mathrm{ppm}$ of deoxynivalenol was observed, which is associated with malting quality [93].

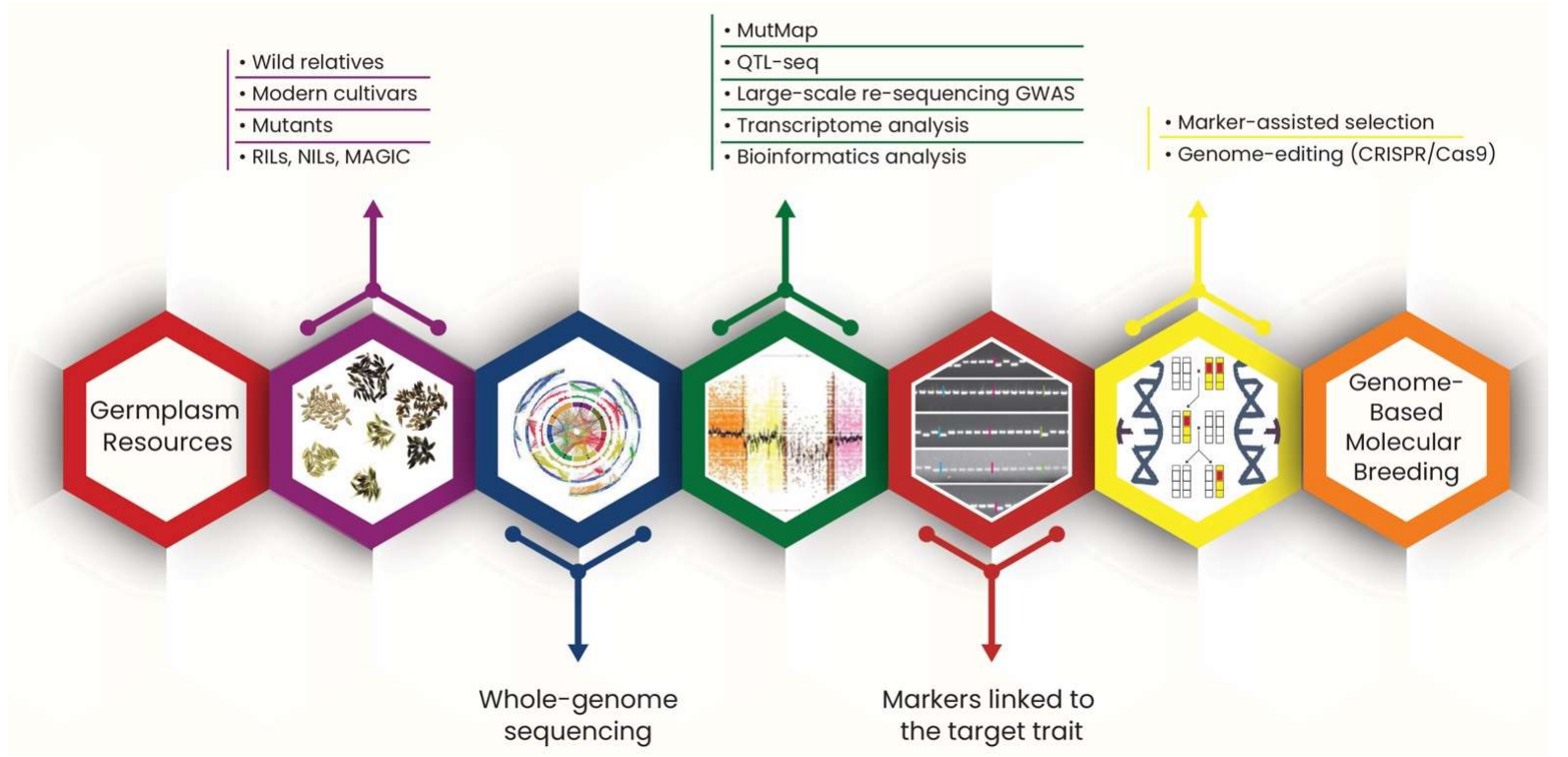

Figure 3. A schematic infographic explaining the process of genome-based molecular breeding. 


\section{Genome Editing, Characterization, and Functional Validation of Identified Genes}

Genome editing has a history of challenges, particularly in complex genomic structures in plant molecular biology. The modern application of genome editing could support traditional breeding without developing the transgenes by overcoming the limit of mutagenesis, which induces a random mutation that is not always useful. In crops, there are several methods of performing mutagenesis in order to develop mutant material for genetic studies. Some of them are unclear about their underlying genetic mechanisms, which can be overcome by modern genome editing [94]. In genome editing, three major technologies are (i) zinc finger nuclease (ZFN), where an endonuclease linked with a multi-zinc-finger DNA-binding domain specifically recognizes and cuts target DNA [95], (ii) transcriptionactivator-like effector nuclease (TALEN), where multiple transcription-factor-like domains bind an endonuclease domain that recognizes target DNA sequences [96], and (iii) the widely used CRISPR/Cas9, where multiple genes can be specifically targeted by using synthetic guide RNA (sgRNA), which can be easily constructed with a chemical synthesis method [97] using chimeric sgRNA or dual RNA (crRNA:tracrRNA) [98].

CRISPR-Cas9 is, so far, the most promising and versatile genome-editing technology; the Cas protein uses the sgRNA to bind to a targeted DNA site, followed by dsDNA cutting [99]. The DNA break can be repaired in two ways: a non-homologous end-joining (NHEJ) repair that creates random insertions and deletions (indels), resulting in mutations through targeted gene knock-outs [100,101], and a homology-directed (HR) repair, which is more precise in the exchange of homologous sequences, resulting in knocked-in genes [102]. Gene-editing knowledge may be used in two ways. First, the detailed molecular and physiological study of edited knock-out and knock-in mutants can assist in further explaining the molecular functions and interactions of genes that are important in barley breeding. Second, edited genes that exhibit a proven trait-improving effect without adverse side effects may be introduced into barley breeding programs, provided that the national legal regulations permit the release of genome-edited cultivars. In barley, target genes can be knocked out after selecting the appropriate $\mathrm{sgRNA}$ sequence from available genome sequence databases or after re-sequencing the target gene from a particular barley cultivar $[103,104]$. Numerous genome-editing studies have been carried out in barley with CRISPR/Cas9, such as the increase in phytase activity in seeds by stacking the PAPHY_a gene [105], regulation of the cytokinin metabolism gene $H v C K X 1 / 3$ [106], validation of the 2OGO gene responsible for fusarium head blight disease [107], functional dissection of biosynthesis of vitamin-Erelated genes (HGGT/HPT) [108], and validation of the viral-resistant gene HvMORC1 in barley [109].

\section{Conclusions}

Despite steady progress in barley breeding, there is still a great need for improving barley cultivars that are adapted to diverse growing conditions. Recent progress in genomics research has provided geneticists, biologists, and breeders with a number of modern tools and technologies that impart precision and efficiency to breeding programs. The assembly of the first barley reference genome offered certain opportunities for the application of genomics in plant breeding. Several molecular, bioinformatics-, and genomics-based approaches that use genomic information in combination with sequencing, re-sequencing, and genotyping datasets are being utilized to study important agricultural traits and their linked genes. Genomic annotation of barley faces the problem of unclear functional information; for example, knowledge of the biochemical activities of many agronomic-trait-related genes is lacking, which could be inferable from proteins encoded with specific domains. A major challenge is to (i) functionally characterize the genes linked to molecular and morphological traits associated with variant forms and (ii) annotate the functional data of the causative genes in the appropriate gene databases. Notwithstanding these challenges, the continuous improvement of gene-editing technologies, with the best example being CRISPR/Cas9, has provided a strong foundation for overcoming these limitations. The recently developed high-quality genome assembly of the Golden Promise 
cultivar is an emerging focus for genome-editing experiments by the barley research community. Future sequencing technologies should drive the further improvement of available reference assemblies and sequence additional barley cultivars and wild barley accessions. This will perfectly facilitate the development of a definitive catalogue of genomic diversity information with large-scale variation and the identification of a rich source of usable genes.

Author Contributions: A.R. and F.K. wrote the manuscript; A.R., K.P., and A.B. revised the manuscript. F.D. and A.M.A. designed and supervised the study. All authors have read and agreed to the published version of the manuscript.

Funding: This work was funded by the National Key R\&D Program of China (2018YFD1000706), the National Natural Science Foundation of China (31871607), and the German Federal Ministry of Research and Education (BMBF) IPAS grant BARLEY-DIVERSITY (FZ 031A352A).

Acknowledgments: We are thankful to Iftikhar Mehdi for helping with the figure designs.

Conflicts of Interest: The authors have no conflict of interest to declare. We certify that the submission is original work and is not under review by any other publication.

\section{References}

1. Purugganan, M.D.; Fuller, D.Q. The nature of selection during plant domestication. Nature 2009, 457, 843-848. [CrossRef]

2. Grando, S.; Macpherson, H.G. Food Barley: Importance, Uses and Local Knowledge; ICARDA: Aleppo, Syria, 2005.

3. Nevo, E.; Fu, Y.-B.; Pavlicek, T.; Khalifa, S.; Tavasi, M.; Beiles, A. Evolution of wild cereals during 28 years of global warming in Israel. Proc. Natl. Acad. Sci. USA 2012, 109, 3412-3415. [CrossRef]

4. Ye, L.; Wang, Y.; Long, L.; Luo, H.; Shen, Q.; Broughton, S.; Wu, D.; Shu, X.; Dai, F.; Li, C. A Trypsin Family protein gene controls tillering and leaf shape in barley. Plant Physiol. 2019, 181, 701-713. [CrossRef] [PubMed]

5. Sreenivasulu, N.; Schnurbusch, T. A genetic playground for enhancing grain number in cereals. Trends Plant Sci. 2012, 17, 91-101. [CrossRef] [PubMed]

6. Alqudah, A.M.; Koppolu, R.; Wolde, G.M.; Graner, A.; Schnurbusch, T. The genetic architecture of barley plant stature. Front. Genet. 2016, 7, 117. [CrossRef] [PubMed]

7. Singh, B.; Mehta, S.; Aggarwal, S.K.; Tiwari, M.; Bhuyan, S.I.; Bhatia, S.; Islam, M.A. Barley, disease resistance, and molecular breeding approaches. In Disease Resistance in Crop Plants; Springer: Berlin/Heidelberg, Germany, 2019; pp. 261-299.

8. Gürel, F.; Öztürk, Z.N.; Uçarlı, C.; Rosellini, D. Barley genes as tools to confer abiotic stress tolerance in crops. Front. Plant Sci. 2016, 7, 1137. [CrossRef] [PubMed]

9. Looseley, M.E.; Ramsay, L.; Bull, H.; Swanston, J.S.; Shaw, P.D.; Macaulay, M.; Booth, A.; Russell, J.R.; Waugh, R.; Thomas, W.T. Association mapping of malting quality traits in UK spring and winter barley cultivar collections. Theor. Appl. Genet. 2020, 133, 2567-2582. [CrossRef] [PubMed]

10. Jaganathan, D.; Bohra, A.; Thudi, M.; Varshney, R.K. Fine mapping and gene cloning in the post-NGS era: Advances and prospects. Theor. Appl. Genet. 2020, 133, 1791-1810. [CrossRef]

11. Goff, S.A.; Ricke, D.; Lan, T.-H.; Presting, G.; Wang, R.; Dunn, M.; Glazebrook, J.; Sessions, A.; Oeller, P.; Varma, H. A draft sequence of the rice genome (Oryza sativa L. ssp. japonica). Science 2002, 296, 92-100. [CrossRef]

12. Consortium, I.W.G.S. A chromosome-based draft sequence of the hexaploid bread wheat (Triticum aestivum) genome. Science 2014, 345, 1251788 .

13. Chandler, V.L.; Brendel, V. The maize genome sequencing project. Plant Physiol. 2002, 130, 1594-1597. [CrossRef] [PubMed]

14. Jayakodi, M.; Padmarasu, S.; Haberer, G.; Bonthala, V.S.; Gundlach, H.; Monat, C.; Lux, T.; Kamal, N.; Lang, D.; Himmelbach, A. The barley pan-genome reveals the hidden legacy of mutation breeding. Nature 2020, 588, 284-289. [CrossRef] [PubMed]

15. Magwene, P.M.; Willis, J.H.; Kelly, J.K. The statistics of bulk segregant analysis using next generation sequencing. PLoS Comput. Biol. 2011, 7, e1002255. [CrossRef] [PubMed]

16. Klein, H.; Xiao, Y.; Conklin, P.A.; Govindarajulu, R.; Kelly, J.A.; Scanlon, M.J.; Whipple, C.J.; Bartlett, M. Bulked-segregant analysis coupled to whole genome sequencing (BSA-Seq) for rapid gene cloning in maize. G3 Genes Genomes Genet. 2018, 8, 3583-3592. [CrossRef]

17. Qi, J.; Ni, F.; Wang, X.; Sun, M.; Cui, Y.; Wu, J.; Caplan, A.; Fu, D. The anther-specific CYP704B is potentially responsible for MSG26 male sterility in barley. Theor. Appl. Genet. 2019, 132, 2413-2423. [CrossRef]

18. Qin, D.; Dong, J.; Xu, F.; Guo, G.; Ge, S.; Xu, Q.; Xu, Y.; Li, M. Characterization and fine mapping of a novel barley stage green-revertible albino gene (HvSGRA) by bulked segregant analysis based on SSR assay and specific length amplified fragment sequencing. BMC Genom. 2015, 16, 838. [CrossRef]

19. Tsai, H.-Y.; Janss, L.L.; Andersen, J.R.; Orabi, J.; Jensen, J.D.; Jahoor, A.; Jensen, J. Genomic prediction and GWAS of yield, quality and disease-related traits in spring barley and winter wheat. Sci. Rep. 2020, 10, 1-15. [CrossRef]

20. Liu, H.-J.; Jian, L.; Xu, J.; Zhang, Q.; Zhang, M.; Jin, M.; Peng, Y.; Yan, J.; Han, B.; Liu, J. High-Throughput CRISPR/Cas9 Mutagenesis Streamlines Trait Gene Identification in Maize. Plant Cell 2020, 32, 1397-1413. [CrossRef] 
21. Chen, K.; Wang, Y.; Zhang, R.; Zhang, H.; Gao, C. CRISPR/Cas genome editing and precision plant breeding in agriculture. Annu. Rev. Plant Biol. 2019, 70, 667-697. [CrossRef]

22. Consortium, I.B.G.S. A physical, genetic and functional sequence assembly of the barley genome. Nature 2012, 491, 711-716.

23. Mascher, M.; Gundlach, H.; Himmelbach, A.; Beier, S.; Twardziok, S.O.; Wicker, T.; Radchuk, V.; Dockter, C.; Hedley, P.E.; Russell, J. A chromosome conformation capture ordered sequence of the barley genome. Nature 2017, 544, 427-433. [CrossRef] [PubMed]

24. Howe, K.L.; Contreras-Moreira, B.; De Silva, N.; Maslen, G.; Akanni, W.; Allen, J.; Alvarez-Jarreta, J.; Barba, M.; Bolser, D.M.; Cambell, L. Ensembl genomes 2020-Enabling non-vertebrate genomic research. Nucleic Acids Res. 2020, 48, D689-D695. [CrossRef] [PubMed]

25. Tello-Ruiz, M.K.; Stein, J.; Wei, S.; Youens-Clark, K.; Jaiswal, P.; Ware, D. Gramene: A resource for comparative analysis of plants genomes and pathways. In Plant Bioinformatics; Springer: Berlin/Heidelberg, Germany, 2016; pp. 141-163.

26. Mascher, M.; Richmond, T.A.; Gerhardt, D.J.; Himmelbach, A.; Clissold, L.; Sampath, D.; Ayling, S.; Steuernagel, B.; Pfeifer, M.; D'Ascenzo, M. Barley whole exome capture: A tool for genomic research in the genus Hordeum and beyond. Plant J. 2013, 76, 494-505. [CrossRef] [PubMed]

27. Mascher, M.; Muehlbauer, G.J.; Rokhsar, D.S.; Chapman, J.; Schmutz, J.; Barry, K.; Muñoz-Amatriaín, M.; Close, T.J.; Wise, R.P.; Schulman, A.H. Anchoring and ordering NGS contig assemblies by population sequencing (POPSEQ). Plant J. 2013, 76, 718-727. [CrossRef] [PubMed]

28. O'Sullivan, H.G. A Genomic Database for Triticeae and Avena. Plant Bioinformatics: Methods and Protocols. Methods in Molecular Biology; Springer: Berlin/Heidelberg, Germany, 2007; pp. 301-314.

29. Tan, C.; Chapman, B.; Wang, P.; Zhang, Q.; Zhou, G.; Zhang, X.-q.; Barrero, R.A.; Bellgard, M.I.; Li, C. BarleyVarDB: A database of barley genomic variation. Database 2020, 2020. [CrossRef]

30. Hill, W.G.; Mackay, T.F. DS Falconer and Introduction to quantitative genetics. Genetics 2004, 167, 1529-1536. [CrossRef] [PubMed]

31. Haley, C.S.; Knott, S.A. A simple regression method for mapping quantitative trait loci in line crosses using flanking markers. Heredity 1992, 69, 315. [CrossRef]

32. Lander, E.S.; Botstein, D. Mapping mendelian factors underlying quantitative traits using RFLP linkage maps. Genetics 1989, 121, 185-199. [CrossRef] [PubMed]

33. Maloy, S.; Hughes, K. Brenner's Encyclopedia of Genetics; Academic Press: Cambridge, MA, USA, 2013.

34. Backes, G.; Graner, A.; Foroughi-Wehr, B.; Fischbeck, G.; Wenzel, G.; Jahoor, A. Localization of quantitative trait loci (QTL) for agronomic important characters by the use of a RFLP map in barley (Hordeum vulgare L.). Theor. Appl. Genet. 1995, 90, 294-302. [CrossRef]

35. Graner, A.; Jahoor, A.; Schondelmaier, J.; Siedler, H.; Pillen, K.; Fischbeck, G.; Wenzel, G.; Herrmann, R. Construction of an RFLP map of barley. Theor. Appl. Genet. 1991, 83, 250-256. [CrossRef]

36. Russell, J.; Fuller, J.; Young, G.; Thomas, B.; Macaulay, M.; Waugh, R.; Powell, W.; Taramino, G. Discriminating between barley genotypes using microsatellite markers. Genome 1997, 40, 442-450. [CrossRef]

37. Honsdorf, N.; March, T.J.; Berger, B.; Tester, M.; Pillen, K. High-throughput phenotyping to detect drought tolerance QTL in wild barley introgression lines. PLoS ONE 2014, 9, e97047. [CrossRef] [PubMed]

38. Ogrodowicz, P.; Adamski, T.; Mikołajczak, K.; Kuczyńska, A.; Surma, M.; Krajewski, P.; Sawikowska, A.; Górny, A.G.; Gudyś, K.; Szarejko, I. QTLs for earliness and yield-forming traits in the Lubuski× CamB barley RIL population under various water regimes. J. Appl. Genet. 2017, 58, 49-65. [CrossRef] [PubMed]

39. Huang, Y.; Haas, M.; Heinen, S.; Steffenson, B.J.; Smith, K.P.; Muehlbauer, G.J. QTL mapping of fusarium head blight and correlated agromorphological traits in an elite barley cultivar Rasmusson. Front. Plant Sci. 2018, 9, 1260. [CrossRef]

40. Gao, S.; Xia, J.; Yuan, S.; Shen, Y.; Zhong, X.; Zhang, S.; Li, Y.; Hu, D.; Zeng, J.; Lan, T. Novel QTL Conferring Phosphorus Acquisition and Utilization Efficiencies in Barley. Front. Genet. 2020, 11, 1039. [CrossRef] [PubMed]

41. Kindu, G.A.; Tang, J.; Yin, X.; Struik, P.C. Quantitative trait locus analysis of nitrogen use efficiency in barley (Hordeum vulgare L.). Euphytica 2014, 199, 207-221. [CrossRef]

42. Karunarathne, S.D.; Han, Y.; Zhang, X.-Q.; Li, C. Advances in understanding the molecular mechanisms and potential genetic improvement for nitrogen use efficiency in barley. Agronomy 2020, 10, 662. [CrossRef]

43. Ye, L.; Huang, Y.; Hu, H.; Dai, F.; Zhang, G. Identification of QTLs associated with haze active proteins in barley. Euphytica 2015, 205, 799-807. [CrossRef]

44. von Korff, M.; Wang, H.; Léon, J.; Pillen, K. AB-QTL analysis in spring barley: III. Identification of exotic alleles for the improvement of malting quality in spring barley (H. vulgare ssp. spontaneum). Mol. Breed. 2008, 21, 81-93. [CrossRef]

45. Cai, S.; Han, Z.; Huang, Y.; Hu, H.; Dai, F.; Zhang, G. Identification of quantitative trait loci for the phenolic acid contents and their association with agronomic traits in Tibetan wild barley. J. Agric. Food Chem. 2016, 64, 980-987. [CrossRef]

46. Liu, H.; Bayer, M.; Druka, A.; Russell, J.R.; Hackett, C.A.; Poland, J.; Ramsay, L.; Hedley, P.E.; Waugh, R. An evaluation of genotyping by sequencing (GBS) to map the Breviaristatum-e (ari-e) locus in cultivated barley. BMC Genom. 2014, 15, 104. [CrossRef] [PubMed]

47. Jannink, J.-L.; Bink, M.C.; Jansen, R.C. Using complex plant pedigrees to map valuable genes. Trends Plant Sci. 2001, 6, 337-342. [CrossRef]

48. Huang, X.; Han, B. Natural variations and genome-wide association studies in crop plants. Annu. Rev. Plant Biol. 2014, 65, 531-551. [CrossRef] [PubMed] 
49. Kaler, A.S.; Gillman, J.D.; Beissinger, T.; Purcell, L.C. Comparing different statistical models and multiple testing corrections for association mapping in soybean and maize. Front. Plant Sci. 2020, 10, 1794. [CrossRef] [PubMed]

50. Caldwell, K.S.; Russell, J.; Langridge, P.; Powell, W. Extreme population-dependent linkage disequilibrium detected in an inbreeding plant species, Hordeum vulgare. Genetics 2006, 172, 557-567. [CrossRef] [PubMed]

51. Bayer, M.M.; Rapazote-Flores, P.; Ganal, M.; Hedley, P.E.; Macaulay, M.; Plieske, J.; Ramsay, L.; Russell, J.; Shaw, P.D.; Thomas, W. Development and evaluation of a barley 50k iSelect SNP array. Front. Plant Sci. 2017, 8, 1792. [CrossRef] [PubMed]

52. Alqudah, A.M.; Sharma, R.; Pasam, R.K.; Graner, A.; Kilian, B.; Schnurbusch, T. Genetic dissection of photoperiod response based on GWAS of pre-anthesis phase duration in spring barley. PLoS ONE 2014, 9, e113120. [CrossRef] [PubMed]

53. Wang, M.; Jiang, N.; Jia, T.; Leach, L.; Cockram, J.; Waugh, R.; Ramsay, L.; Thomas, B.; Luo, Z. Genome-wide association mapping of agronomic and morphologic traits in highly structured populations of barley cultivars. Theor. Appl. Genet. 2012, 124, 233-246. [CrossRef] [PubMed]

54. Gutiérrez, L.; Germán, S.; Pereyra, S.; Hayes, P.M.; Pérez, C.A.; Capettini, F.; Locatelli, A.; Berberian, N.M.; Falconi, E.E.; Estrada, R. Multi-environment multi-QTL association mapping identifies disease resistance QTL in barley germplasm from Latin America. Theor. Appl. Genet. 2015, 128, 501-516. [CrossRef] [PubMed]

55. Gutiérrez, L.; Cuesta-Marcos, A.; Castro, A.J.; von Zitzewitz, J.; Schmitt, M.; Hayes, P.M. Association mapping of malting quality quantitative trait loci in winter barley: Positive signals from small germplasm arrays. Plant Genome 2011, 4, 256-272. [CrossRef]

56. Maurer, A.; Draba, V.; Jiang, Y.; Schnaithmann, F.; Sharma, R.; Schumann, E.; Kilian, B.; Reif, J.C.; Pillen, K. Modelling the genetic architecture of flowering time control in barley through nested association mapping. BMC Genom. 2015, 16, 1-12. [CrossRef]

57. Sannemann, W.; Huang, B.E.; Mathew, B.; Léon, J. Multi-parent advanced generation inter-cross in barley: High-resolution quantitative trait locus mapping for flowering time as a proof of concept. Mol. Breed. 2015, 35, 1-16. [CrossRef]

58. Wiegmann, M.; Maurer, A.; Pham, A.; March, T.J.; Al-Abdallat, A.; Thomas, W.T.B.; Bull, H.J.; Shahid, M.; Eglinton, J.; Baum, M.; et al. Barley yield formation under abiotic stress depends on the interplay between flowering time genes and environmental cues. Sci. Rep. 2019, 9, 6397. [CrossRef]

59. Dreissig, S.; Maurer, A.; Sharma, R.; Milne, L.; Flavell, A.J.; Schmutzer, T.; Pillen, K. Natural variation in meiotic recombination rate shapes introgression patterns in intraspecific hybrids between wild and domesticated barley. New Phytol. 2020, 228, 1852-1863. [CrossRef] [PubMed]

60. Würschum, T.; Langer, S.M.; Longin, C.F.H.; Korzun, V.; Akhunov, E.; Ebmeyer, E.; Schachschneider, R.; Schacht, J.; Kazman, E.; Reif, J.C. Population structure, genetic diversity and linkage disequilibrium in elite winter wheat assessed with SNP and SSR markers. Theor. Appl. Genet. 2013, 126, 1477-1486. [CrossRef] [PubMed]

61. Wray, N.R.; Yang, J.; Hayes, B.J.; Price, A.L.; Goddard, M.E.; Visscher, P.M. Pitfalls of predicting complex traits from SNPs. Nat. Rev. Genet. 2013, 14, 507-515. [CrossRef] [PubMed]

62. Qian, L.; Hickey, L.T.; Stahl, A.; Werner, C.R.; Hayes, B.; Snowdon, R.J.; Voss-Fels, K.P. Exploring and harnessing haplotype diversity to improve yield stability in crops. Front. Plant Sci. 2017, 8, 1534. [CrossRef]

63. Abed, A.; Belzile, F. Comparing Single-SNP, Multi-SNP, and Haplotype-Based Approaches in Association Studies for Major Traits in Barley. Plant Genome 2019, 12, 190036. [CrossRef]

64. Bradbury, P.; Parker, T.; Hamblin, M.T.; Jannink, J.L. Assessment of power and false discovery rate in genome-wide association studies using the BarleyCAP germplasm. Crop Sci. 2011, 51, 52-59. [CrossRef]

65. Pauli, D.; Muehlbauer, G.J.; Smith, K.P.; Cooper, B.; Hole, D.; Obert, D.E.; Ullrich, S.E.; Blake, T.K. Association mapping of agronomic QTLs in US spring barley breeding germplasm. Plant Genome 2014, 7, 1-15. [CrossRef]

66. Waugh, R.; Jannink, J.-L.; Muehlbauer, G.J.; Ramsay, L. The emergence of whole genome association scans in barley. Curr. Opin. Plant Biol. 2009, 12, 218-222. [CrossRef]

67. Alqudah, A.M.; Sallam, A.; Baenziger, P.S.; Börner, A. GWAS: Fast-forwarding gene identification and characterization in temperate Cereals: Lessons from Barley-A review. J. Adv. Res. 2020, 22, 119-135. [CrossRef]

68. Guo, T.; Yang, J.; Li, D.; Sun, K.; Luo, L.; Xiao, W.; Wang, J.; Liu, Y.; Wang, S.; Wang, H. Integrating GWAS, QTL, mapping and RNA-seq to identify candidate genes for seed vigor in rice (Oryza sativa L.). Mol. Breed. 2019, 39, 1-16. [CrossRef]

69. Baxevanis, A.D.; Bader, G.D.; Wishart, D.S. Bioinformatics; John Wiley \& Sons: Hoboken, NJ, USA, 2020.

70. Van Sluys, M.; Monteiro-Vitorello, C.; Camargo, L.; Menck, C.; Da Silva, A.; Ferro, J.; Oliveira, M.; Setubal, J.; Kitajima, J.; Simpson, A. Comparative genomic analysis of plant-associated bacteria. Annu. Rev. Phytopathol. 2002, 40, 169-189. [CrossRef] [PubMed]

71. Vandepoele, K.; Raes, J.; De Veylder, L.; Rouzé, P.; Rombauts, S.; Inzé, D. Genome-wide analysis of core cell cycle genes in Arabidopsis. Plant Cell 2002, 14, 903-916. [CrossRef]

72. Riechmann, J.L.; Heard, J.; Martin, G.; Reuber, L.; Jiang, C.-Z.; Keddie, J.; Adam, L.; Pineda, O.; Ratcliffe, O.; Samaha, R. Arabidopsis transcription factors: Genome-wide comparative analysis among eukaryotes. Science 2000, 290, 2105-2110. [CrossRef] [PubMed]

73. Chattha, W.S.; Atif, R.M.; Iqbal, M.; Shafqat, W.; Farooq, M.A.; Shakeel, A. Genome-wide identification and evolution of Dof transcription factor family in cultivated and ancestral cotton species. Genomics 2020, 112, 4155-4170. [CrossRef] [PubMed]

74. Finn, R.D.; Clements, J.; Eddy, S.R. HMMER web server: Interactive sequence similarity searching. Nucleic Acids Res. 2011, 39, W29-W37. [CrossRef]

75. Cui, L.; Yang, G.; Yan, J.; Pan, Y.; Nie, X. Genome-wide identification, expression profiles and regulatory network of MAPK cascade gene family in barley. BMC Genom. 2019, 20, 750. [CrossRef] [PubMed] 
76. Panahi, B.; Mohammadi, S.A.; Ruzicka, K.; Holaso, H.A.; Mehrjerdi, M.Z. Genome-wide identification and co-expression network analysis of nuclear factor-Y in barley revealed potential functions in salt stress. Physiol. Mol. Biol. Plants 2019, 25, 485-495. [CrossRef]

77. Tong, T.; Fang, Y.-x.; Zhang, Z.; Zheng, J.; Zhang, X.; Li, J.; Niu, C.; Xue, D.; Zhang, X. Genome-wide identification and expression pattern analysis of the KCS gene family in barley. Plant Growth Regul. 2021, 93, 89-103. [CrossRef]

78. Li, J.; Liu, X. Genome-wide identification and expression profile analysis of the Hsp20 gene family in Barley (Hordeum vulgare L.). PeerJ 2019, 7, e6832. [CrossRef] [PubMed]

79. Cao, F.; Chen, F.; Sun, H.; Zhang, G.; Chen, Z.-H.; Wu, F. Genome-wide transcriptome and functional analysis of two contrasting genotypes reveals key genes for cadmium tolerance in barley. BMC Genom. 2014, 15, 1-14. [CrossRef]

80. Tombuloglu, H. Genome-wide analysis of the auxin response factors (ARF) gene family in barley (Hordeum vulgare L.). J. Plant Biochem. Biotechnol. 2019, 28, 14-24. [CrossRef]

81. Bernardo, R. Breeding for Quantitative Traits in Plants; Stemma Press: Woodbury, MN, USA, 2002; Volume 1.

82. Charcosset, A. Marker-assisted introgression of quantitative trait loci. Genetics 1997, 147, 1469-1485.

83. Ben-Ari, G.; Lavi, U. Marker-assisted selection in plant breeding. In Plant Biotechnology and Agriculture; Elsevier: Amsterdam, The Netherlands, 2012; pp. 163-184.

84. Hospital, F. Selection in backcross programmes. Philos. Trans. R. Soc. B Biol. Sci. 2005, 360, 1503-1511. [CrossRef] [PubMed]

85. Guimarães, E.P. Marker-Assisted Selection: Current Status and Future Perspectives in Crops, Livestock, Forestry and Fish; Food \& Agriculture Organization: Rome, Italy, 2007.

86. Xu, Y.; Zhang, X.-Q.; Harasymow, S.; Westcott, S.; Zhang, W.; Li, C. Molecular marker-assisted backcrossing breeding: An example to transfer a thermostable $\beta$-amylase gene from wild barley. Mol. Breed. 2018, 38, 1-9. [CrossRef]

87. Dabbert, T.; Okagaki, R.J.; Cho, S.; Boddu, J.; Muehlbauer, G.J. The genetics of barley low-tillering mutants: Absent lower laterals (als). Theor. Appl. Genet. 2009, 118, 1351-1360. [CrossRef]

88. Abou-Elwafa, S.F. Association mapping for yield and yield-contributing traits in barley under drought conditions with genomebased SSR markers. Comptes Rendus Biol. 2016, 339, 153-162. [CrossRef]

89. Long, N.V.; Dolstra, O.; Malosetti, M.; Kilian, B.; Graner, A.; Visser, R.G.; van der Linden, C.G. Association mapping of salt tolerance in barley (Hordeum vulgare L.). Theor. Appl. Genet. 2013, 126, 2335-2351. [CrossRef]

90. Jia, Q.; Tan, C.; Wang, J.; Zhang, X.-Q.; Zhu, J.; Luo, H.; Yang, J.; Westcott, S.; Broughton, S.; Moody, D. Marker development using SLAF-seq and whole-genome shotgun strategy to fine-map the semi-dwarf gene ari-e in barley. BMC Genom. 2016, 17, 911. [CrossRef]

91. Schmid, K.J.; Thorwarth, P. Genomic selection in barley breeding. In Biotechnological Approaches to Barley Improvement; Springer: Berlin/Heidelberg, Germany, 2014; pp. 367-378.

92. Bernardo, R. Bandwagons I, too, have known. Theor. Appl. Genet. 2016, 129, 2323-2332. [CrossRef]

93. Tiede, T.; Smith, K.P. Evaluation and retrospective optimization of genomic selection for yield and disease resistance in spring barley. Mol. Breed. 2018, 38, 1-16. [CrossRef]

94. Ohnoutkova, L. Mutation breeding in barley: Historical overview. In Barley; Springer: Berlin/Heidelberg, Germany, 2019; pp. 7-19.

95. Kim, Y.-G.; Cha, J.; Chandrasegaran, S. Hybrid restriction enzymes: Zinc finger fusions to Fok I cleavage domain. Proc. Natl. Acad. Sci. USA 1996, 93, 1156-1160. [CrossRef] [PubMed]

96. Christian, M.; Cermak, T.; Doyle, E.L.; Schmidt, C.; Zhang, F.; Hummel, A.; Bogdanove, A.J.; Voytas, D.F. Targeting DNA double-strand breaks with TAL effector nucleases. Genetics 2010, 186, 757-761. [CrossRef]

97. Ryan, D.E.; Taussig, D.; Steinfeld, I.; Phadnis, S.M.; Lunstad, B.D.; Singh, M.; Vuong, X.; Okochi, K.D.; McCaffrey, R.; Olesiak, M. Improving CRISPR-Cas specificity with chemical modifications in single-guide RNAs. Nucleic Acids Res. 2018, 46, 792-803. [CrossRef]

98. Arroyo, J.D.; Jourdain, A.A.; Calvo, S.E.; Ballarano, C.A.; Doench, J.G.; Root, D.E.; Mootha, V.K. A genome-wide CRISPR death screen identifies genes essential for oxidative phosphorylation. Cell Metab. 2016, 24, 875-885. [CrossRef]

99. Agrotis, A.; Ketteler, R. A new age in functional genomics using CRISPR/Cas9 in arrayed library screening. Front. Genet. 2015, 6, 300. [CrossRef]

100. Feng, Z.; Zhang, B.; Ding, W.; Liu, X.; Yang, D.-L.; Wei, P.; Cao, F.; Zhu, S.; Zhang, F.; Mao, Y. Efficient genome editing in plants using a CRISPR/Cas system. Cell Res. 2013, 23, 1229-1232. [CrossRef] [PubMed]

101. Bortesi, L.; Fischer, R. The CRISPR/Cas9 system for plant genome editing and beyond. Biotechnol. Adv. 2015, 33, 41-52. [CrossRef]

102. Baltes, N.J.; Gil-Humanes, J.; Cermak, T.; Atkins, P.A.; Voytas, D.F. DNA replicons for plant genome engineering. Plant Cell 2014, 26, 151-163. [CrossRef]

103. Lawrenson, T.; Harwood, W.A. Creating targeted gene knockouts in barley using CRISPR/Cas9. In Barley; Springer: Berlin/Heidelberg, Germany, 2019; pp. 217-232.

104. Lawrenson, T.; Shorinola, O.; Stacey, N.; Li, C.; Østergaard, L.; Patron, N.; Uauy, C.; Harwood, W. Induction of targeted, heritable mutations in barley and Brassica oleracea using RNA-guided Cas9 nuclease. Genome Biol. 2015, 16, 258. [CrossRef] [PubMed]

105. Holme, I.B.; Madsen, C.K.; Wendt, T.; Brinch-Pedersen, H. Horizontal stacking of PAPhy_a cisgenes in barley is a potent strategy for increasing mature grain phytase activity. Front. Plant Sci. 2020, 11, 592139. [CrossRef] 
106. Gasparis, S.; Przyborowski, M.; Kała, M.; Nadolska-Orczyk, A. Knockout of the HvCKX1 or HvCKX3 gene in barley (Hordeum vulgare L.) by RNA-Guided Cas9 Nuclease affects the regulation of cytokinin metabolism and root morphology. Cells $2019,8,782$. [CrossRef] [PubMed]

107. Low, Y.C.; Lawton, M.A.; Di, R. Validation of barley $2 \mathrm{OGO}$ gene as a functional orthologue of Arabidopsis DMR6 gene in Fusarium head blight susceptibility. Sci. Rep. 2020, 10, 1-13. [CrossRef] [PubMed]

108. Zeng, Z.; Han, N.; Liu, C.; Buerte, B.; Zhou, C.; Chen, J.; Wang, M.; Zhang, Y.; Tang, Y.; Zhu, M. Functional dissection of HGGT and HPT in barley vitamin E biosynthesis via CRISPR/Cas9-enabled genome editing. Ann. Bot. 2020, 126, 929-942. [CrossRef]

109. Kumar, N.; Galli, M.; Ordon, J.; Stuttmann, J.; Kogel, K.H.; Imani, J. Further analysis of barley MORC 1 using a highly efficient RNA-guided Cas9 gene-editing system. Plant Biotechnol. J. 2018, 16, 1892-1903. [CrossRef] 